\title{
PSO Fined-tuned Model-Free PID Controller with Derivative Filter for Buck-Converter Driven DC Motor
}

\author{
Mohd Zaidi Mohd Tumari, Amar Faiz Zainal Abidin, A Shamsul Rahimi A Subki, Ab Wafi Ab \\ Aziz, Mohd Ashraf Ahmad, Mohd Riduwan Ghazali
}

\begin{abstract}
Traditionally, the PID controller parameters are tuned heuristically based on time response behavior of the system. This method is tiresome job and can cause undesirable system response. Therefore, this research suggests the tuning method of a model-free PID controller with derivative filter (PIDF) by implementing Particle Swarm Optimization (PSO). This tuning method is applied to buck-converter driven DC motor control. The speed of DC motor is controlled by PIDF controller. The parameters of PIDF controller are fine-tuned by implementing PSO algorithms. The fitness functions of the algorithm are evaluated based on Sum Square Error (SSE) and Sum Absolute Error $(\mathrm{SAE})$. The state-space representation of buck-converter/DC motor is considered to confirm the design of the control method. The results of the proposed tuning method are compared with PI controller and PIDF controller tuned by PID Tuner Simulink. The time response specifications of angular velocity, armature current and duty cycle input energy are considered as a control scheme performance. Finally, the suggested tuning technique promises a very minimum duty cycle energy and a fast input tracking of DC motor angular velocity.
\end{abstract}

Index Terms: Buck-converter driven DC motor, derivative filter, PID tuning, PSO.

\section{INTRODUCTION}

The topic of improvise the switching strategy in PWM signals for DC motor speed control is one of the most active areas in power electronics research today. The traditional methods depend on hard switching strategy which generates insufficient dynamic behavior and can cause a very noisy response of the system. This circumstance can lead to large currents which can damage the DC motor and the power supply [1]. Generally, the power supply component is essential for buck-converter/DC motor, so, the control technique for the entire system is necessary. The fusion of

Revised Manuscript Received on August 18, 2019.

Mohd Zaidi Bin Mohd Tumari, Faculty of Electrical \& Electronics Engineering Technology, Universiti Teknikal Malaysia Melaka, Durian Tunggal, Melaka, Malaysia.

Amar Faiz Bin Zainal Abidin, Faculty of Electrical \& Electronics Engineering Technology, Universiti Teknikal Malaysia Melaka, Durian Tunggal, Melaka, Malaysia.

A Shamsul Rahimi Bin A Subki, Faculty of Electrical \& Electronics Engineering Technology, Universiti Teknikal Malaysia Melaka, Durian Tunggal, Melaka, Malaysia.

Ab Wafi Bin Ab Aziz, Faculty of Electrical \& Electronics Engineering Technology, Universiti Teknikal Malaysia Melaka, Durian Tunggal, Melaka, Malaysia.

Mohd Ashraf Bin Ahmad, Faculty of Electrical \& Electronics Engineering, Universiti Malaysia Pahang, Pekan, Pahang, Malaysia.

Mohd Riduwan Bin Ghazali, Faculty of Electrical \& Electronics Engineering, Universiti Malaysia Pahang, Pekan, Pahang, Malaysia.
DC motors with DC to DC power converters has been described in [2]. Furthermore, the combination of DC motor and buck converter with a flatness based approach has been recommended in [3]. Those studies found that the smooth DC output currents and voltages can be produced with very minimal current ripple since the converter comprises a capacitor and a coil as an energy storing elements. Furthermore, the technique to produce a smooth trajectory of DC motor speed by implementing the optimal and intelligent controls have been introduced in $[4,5]$. Thus, it is essential to design the circuit of the converter to have a precise high power conversion rate during tracking of the desired angular velocity. In order to achieve these objectives, several approaches using different method have been proposed. A considerable amount of literature has been published on control of buck-converter driven DC motor. For instance, H-infinity controller [6], data driven sigmoid-based PI controller [7], PI-fuzzy logic controller [8] and adaptive controller based on Lyapunov function [9].

In this study, a PIDF controller is implemented in buck-converter system to control the angular velocity of the DC motor. The linear state space model of the system is derived based on Fig. 1 [1] to design the controller. PIDF controller is well known due to its advantages in solving numerous kinds of control objectives such as input tracking capability, robust stabilization of uncertain systems and disturbance cancellation. PID has been beneficial in many industrial applications such as [10]-[14]. Despite PID controller is able to solve those system control problems, the tuning of PID parameters is very tedious task. So, it is important to decrease the tuning time for PID controller to take full benefits of it. Hence, for optimal tuning of PID gains, soft computing optimization techniques have been implemented during last few decades.

The main objective in this paper is to find the optimal value of PIDF controller parameters so the buck-converter driven DC motor is able to track the smooth reference trajectory precisely with minimum error. PSO is chosen to tune 4 parameters; $K_{p}, K_{i}, K_{d}$ and $\mathrm{N}$ to the optimal values for the desired response of the system. A considered amount of literature has been published on PSO tune PID in a number of applications such as $[15,16]$. Those studies have proved that PSO is a good choice to tune the PID controller in their application. For this study, the performance of the proposed tuning scheme is measured based on the response of armature current, duty cycle and angular velocity. The efficacy of the proposed method is compared with previously published PI controller [8] and PIDF

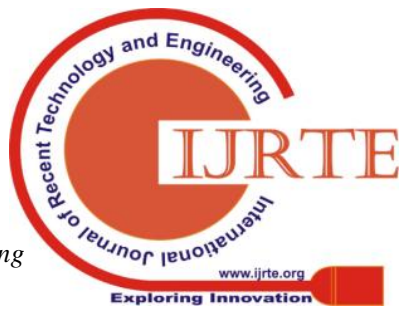


controller tuned by PID Tuner Simulink.

\section{MODELLING OF BUCK-CONVERTER DRIVEN DC MOTOR}

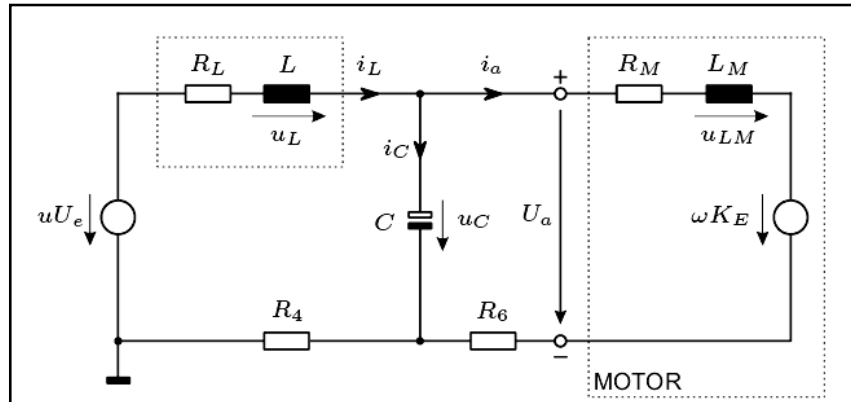

Fig. 1. The Circuit Diagram of Buck-Converter with DC Motor System [1].

A simplified model of buck-converter with DC motor in [1] as shown in Fig. 1 is considered. The ideal switched voltage source is used as a switching devices for the system. This ideal switched voltage is derived by the multiplication of switching variable $u \in\{0,1\}$ with input voltage, $U_{e}$. The ohmic resistance of the coil windings is represent by resistance $R_{L}$. An electromagnetic voltage source $\omega K_{E}$, ohmic resistance $R_{M}$ and inductance $L_{M}$, represent the modelling of the DC motor. The parameters of the DC motor have been determined as $K_{E}=0.0517 \mathrm{~V} / \mathrm{rad} / \mathrm{s}, \quad R_{M}=$ $6 \Omega$ and $L_{M}=8.9 \mathrm{mH}$. The value of switching frequency for the converter is set to $f=45 \mathrm{kHz}$. While, the input voltage $U_{e}$ $=24 \mathrm{~V}$ same as DC motor maximum voltage. The buck converter circuit with capacitance, $C=470 \mu \mathrm{F}$, coil resistance, $R_{L}=0.2 \Omega$ and coil inductance, $L=1.33 \mathrm{mH}$ are used for this study.

A linear fourth order system with mechanical equation of the motor shaft is represented in state space as in (1) to (4).

$$
\dot{\mathbf{x}}=\mathrm{A} \mathbf{x}+\mathrm{B} u
$$

where

$$
\begin{aligned}
& \mathbf{x}=\left[\begin{array}{llll}
i_{L} & u_{C} & i_{a} & \omega
\end{array}\right]^{T} \\
& \mathrm{~A}=\left[\begin{array}{cccc}
-\frac{R_{L}}{L} & -\frac{1}{L} & 0 & 0 \\
\frac{1}{C} & 0 & -\frac{1}{C} & 0 \\
0 & \frac{1}{L_{M}} & -\frac{R_{M}}{L_{M}} & -\frac{K_{E}}{L_{M}} \\
0 & 0 & \frac{K_{M}}{J} & 0
\end{array}\right] \\
& \mathrm{B}=\left[\begin{array}{llll}
\frac{U_{e}}{L} & 0 & 0 & 0
\end{array}\right]^{T}
\end{aligned}
$$

The value of tacho generator and moment of inertia is set to $K_{M}=0.0517 \mathrm{Nm} / \mathrm{A}$ and $J=7.95 \times 10^{-6} \mathrm{~kg} \mathrm{~m}^{2}$, respectively. In (2) to (4), $R_{4}$ and $R_{6}$ can be neglected because of very low values of resistances. The duty ratio $\delta \in\{0,1\}$ of PWM strategy is generated from an analog input signal to replace the discrete input $u \in\{0,1\}$ [17]. Thus, for this study, averaged dynamic model is used as in (5)

$$
\dot{\mathbf{x}}=\mathrm{A} \mathbf{x}+\mathrm{B} \delta
$$

where the new input is the duty cycle $\delta$. The output is in (6)

$$
\omega=\left[\begin{array}{llll}
0 & 0 & 0 & 1
\end{array}\right] \mathbf{x}
$$

It is assuming that the saturation effects did not occurred in the coil to avoid nonlinearly on the current $i_{L}$.

\section{CONTROLLER DESIGN}

\section{A. PIDF Controller}

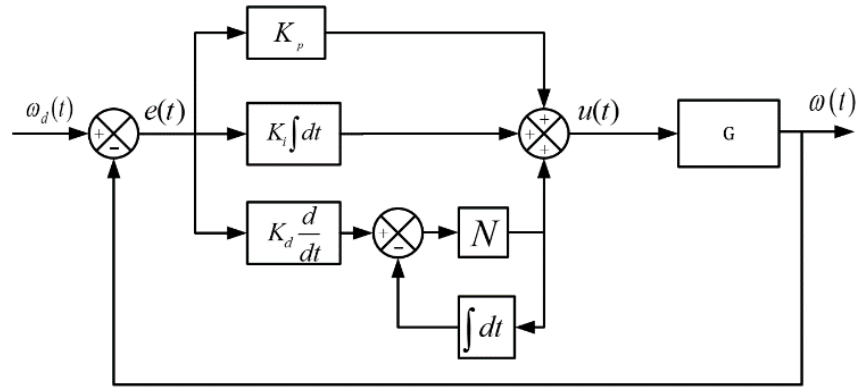

Fig. 2: PIDF control system for buck-converter driven DC motor system

Fig. 2 shows the PIDF control system for buck-converter driven DC motor system, where $\omega(t), u(t), e(t)$ and $\omega_{d}(t)$ are the measurement of angular velocity, the control input, error and reference, respectively. The sensors usually produced noise in high frequency and typically effects the derivative block. Therefore, a low pass filter is added in derivative part. $\mathrm{G}$ block represent the plant of the buck-converter driven DC motor system. The PIDF transfer function is stated in (7)

$$
T F_{P I D}=K_{p}+\frac{K_{i}}{s}+K_{d} \times \frac{N s}{N+s}
$$

where

$K_{d}=$ derivative gain

$K_{i}=$ integral gain

$K_{p}=$ proportional gain

$N=$ filter coefficient

\section{B. Particle Swarm Optimization (PSO)}

PSO is a Swarm Intelligence (SI) algorithm motivated by the swarm of birds and fish schooling. In PSO algorithm, particles as known as agents will travel to it current best location and global best randomly by its current velocity that will be updated randomly later. Hence, to increase the efficiency of the swarm, the global communication between particles and real-number randomness is used in the algorithm.

Let $v_{i}$ and $x_{i}$ is the velocity vector and position vector for agent or particle $i$, respectively. 4 PIDF parameters to be adjusted, so the design parameter is stated in (8)

$$
x_{i}=\left[\begin{array}{llll}
K_{p} & K_{i} & K_{d} & N
\end{array}\right]
$$

Firstly, the particles velocity, $v_{i}$ and swarm particles, $x_{i}$ are set randomly using (9) and (10), respectively, where $u_{b}$ is an upper boundary and $l_{b}$ is a lower boundary set for the agents, while $r_{1}$ and $r_{2}$ is 
random real-number between [0 1].

$$
\begin{gathered}
x_{i}=l_{b}+\left(u_{b}-l_{b}\right) \times r_{1} \\
v_{i}=r_{2}
\end{gathered}
$$

For this simulation, an enhanced PSO algorithm using a priority-based fitness technique is recommended for PIDF tuning [18]. Sum squared error (SSE) of angular velocity, $\omega$ is set as uppermost primacy and sum absolute error (SAE) of angular velocity is set as second priority. The main concern is to get the smallest number of those fitness functions which are as shown in (11) and (12).

$$
\begin{aligned}
& f_{1}(x)=\text { Fitness }_{1}=S S E=\sum e^{2}(t) d t \\
& f_{2}(x)=\text { Fitness }_{2}=S A E=\sum|e|(t) d t
\end{aligned}
$$

The personal best agent is updated based on (13) as

$$
x_{t+1}^{*}=\left\{\begin{array}{c}
x_{t}^{i}, f_{1}\left(x_{t}^{i}\right)<f_{1}\left(X_{t}^{*}\right) \text { AND } f_{2}\left(x_{t}^{i}\right)<f_{2}\left(X_{t}^{*}\right) \\
x_{t}^{*}, \text { otherwise }
\end{array}\right.
$$

The global best is updated by using equation in (14)

$$
g_{t+1}^{*}=\left\{\begin{array}{c}
x_{t}^{i}, f_{1}\left(x_{t}^{i}\right)<f_{1}\left(g_{t}^{*}\right) \text { AND } f_{2}\left(x_{t}^{i}\right)<f_{2}\left(g_{t}^{*}\right) \\
g_{t}^{*}, \text { otherwise }
\end{array}\right.
$$
(15)

$v_{i}^{t+1}=w_{i} \times v_{i}+\alpha \times r_{3} \times\left(g^{*}-x_{i}^{t}\right)+\beta \times r_{4} \times\left(x^{*}-x_{i}^{t}\right)$

where, an inertia function, $w_{i}$ as (16) is used to update the velocity, $v_{i}^{t+1}$ in every new iteration $(t+1)$ per (17) [19], $r_{3}$ and $r_{4}$ is random real-number between [0 1], the parameters $\beta$ and $\alpha$ are the personal coefficient and social coefficient, respectively. Typically, these coefficients are constant and set to 2 .

$$
w_{i}=0.4+0.5 \times \frac{N_{i}-i}{N_{i}}
$$

The new position of the particle is updated by

$$
x_{i}^{t+1}=x_{i}+v_{i}^{t+1}
$$

The simulation stopped after the maximum iteration is reached and the best PID parameters obtained by GWO algorithm is presented.

\section{RESULTS AND DISCUSSION}

The objective of the proposed controller is to achieve a very minimum duty cycle energy and fast input tracking of DC motor angular velocity. Usually, to operate the DC motor from initial angular velocity to desired angular velocity can cause very erroneous transient response. Therefore, a very smooth trajectory is needed where the DC motor is started from $\omega=0$ to a final angular velocity (steady state) smoothly [1]. The boundary conditions (18) of the reference trajectory $\omega_{r}(t)$ for the output is

$$
\omega_{r}(0)=0 \text { and } \omega_{r}\left(t_{d}\right)=\frac{\omega_{\max }}{2},
$$

The very smooth transitions which fulfils the conditions (19), is modeled as

$$
\omega_{r}(t)=\frac{\omega_{\max }}{2}\left[\tanh \eta\left(t-t_{d}\right)+1\right]
$$

Where $t_{d}$ is shifting time, $\eta$ is the constant that determine the smooth profile and $\omega_{\max }$ is the steady state value [20]. For this research, the parameters of the smooth trajectory has been determined which are $t_{d}=100 \mathrm{~ms}, \omega_{\max }=150 \mathrm{rad} / \mathrm{s}$ and $\eta=0.03$.

The simulation works are done with MATLAB 2017b, Microsoft Window 10, 8GB RAM and Intel Core i7-6700 Processor $(3.41 \mathrm{GHz})$. The buck-converter driven DC motor model is designed via Simulink.

The simulation is run for $0.25 \mathrm{~s}$ and the sampling time is $0.01 \mathrm{~s}$. The optimum combination of number of agents and maximum number of iterations are $\mathrm{N}=30$ and $\mathrm{T}=10$ that contributes to 300 number of evaluations. The lower boundary and upper boundary for each design parameters in (8) is fixed as follow:

$$
\begin{aligned}
& \text { lower boundary }=l_{b}=\left[\begin{array}{rrrr}
-1 & -1 & -1 & -1
\end{array}\right] \\
& \text { upper boundary }=u_{b}=\left[\begin{array}{rrrr}
1 & 1 & 1 & 1
\end{array}\right]
\end{aligned}
$$

Efficacy of the PSO tuning is compared with Simulink PID Tuner [21]. Fig. 3 shows the window of Simulink PID Tuner Application. The controller parameters are obtained by changing the slider of transient behavior and response time. Then, the step response is observed carefully to get the best response based on time response specifications. The optimal PIDF parameters obtained by implementing PSO algorithm and Simulink PID Tuner is shown in Table I.

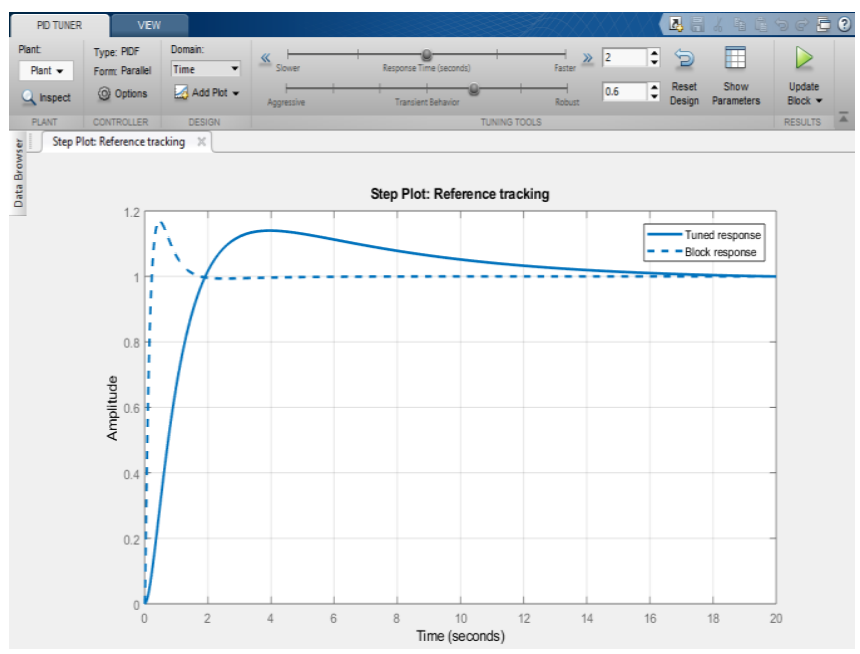

Fig. 3. The Simulink window for PID Tuner Application 
TABLE I: PIDF PARAMETERS OBTAINED By PSO TUNING AND SIMULINK

\begin{tabular}{ccc}
\hline \hline PIDF gain & PSO & Simulink PID Tuner \\
\hline \hline$K_{p}$ & 0.0187 & 0.0034 \\
$K_{i}$ & 0.8076 & 0.2185 \\
$K_{d}$ & 0.0979 & $-5.1443 \times 10^{-6}$ \\
$\mathrm{~N}$ & 0.0198 & 364.5855 \\
\hline \hline
\end{tabular}

For further comparative assessment, the PSO-PIDF controller is compared with the PI controller in [8]. Figs 3 -5 shows the response of angular velocity, duty cycle input energy and armature current, respectively. It is clearly shows in Fig. 3 that all controllers are capable to track the desired velocity from 0 to $150 \mathrm{rad} / \mathrm{s}$. Table II shows the time response specifications for all controllers. It is observed that the integral square error (ISE) and integral absolute error (IAE) of the PSO-PIDF controller is lower as compared to the Simulink PID Tuner and PI controller. With lower ISE and IAE, that's mean, the actuator capable to track the desired angular velocity nicely with minimum error. Fig. 4 shows that the duty cycle response for the PSO-PIDF controller produced more input energy as compared to PIDF controller tuned by PID Tuner Simulink and PI controller. Fig. 5 shows the armature current response of the system. The result reveal that, all controllers produce peak armature current during 100 $\mathrm{ms}$ before settled down at $230 \mathrm{~ms}$. Based on the results, the PSO-PIDF produces the maximum armature current with the value of $0.3516 \mathrm{~A}$, PI controller with the value of $0.3453 \mathrm{~A}$ and PIDF controller tuned by PID Tuner Simulink with the value of 0.3371 . Furthermore, the armature currents for all controllers reach the maximum within transition period. It indicates that during the transition of the angular velocity from zero to final state, the buck converter supplies the highest amount of power to the motor.

TABLE II. TIME RESPONSE SPECIFICATIONS OF PSO-PIDF, SIMULINK-PIDF AND PI CONTROLLER

\begin{tabular}{lllll}
\hline \hline Controller & $\begin{array}{l}\text { Rise time } \\
(\mathbf{m s})\end{array}$ & $\begin{array}{l}\text { Settling time } \\
(\mathbf{m s})\end{array}$ & ISE & IAE \\
\hline \hline PSO-PIDF & 70 & 170 & 0.1592 & 0.399 \\
$\begin{array}{l}\text { SIMULINK- } \\
\text { PIDF }\end{array}$ & 75 & 176 & 2.186 & 1.478 \\
PI & 74 & 171 & 0.6628 & 0.8141 \\
\hline
\end{tabular}

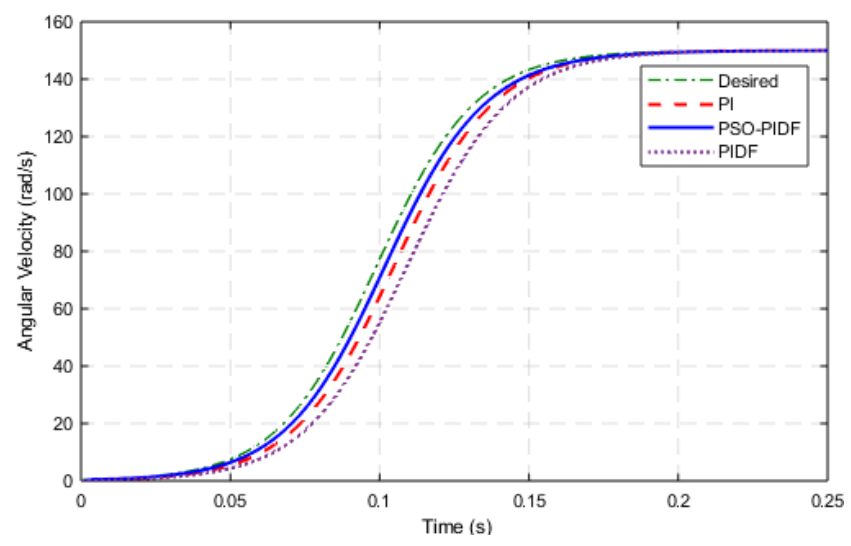

Fig. 3. Angular velocity response for PI, PIDF and PSO-PIDF.

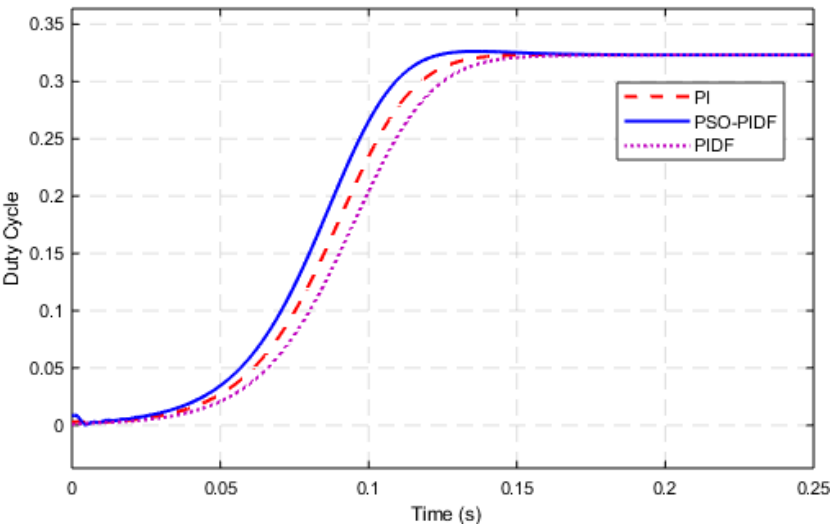

Fig. 4. Duty cycle response for PI and PIDF.

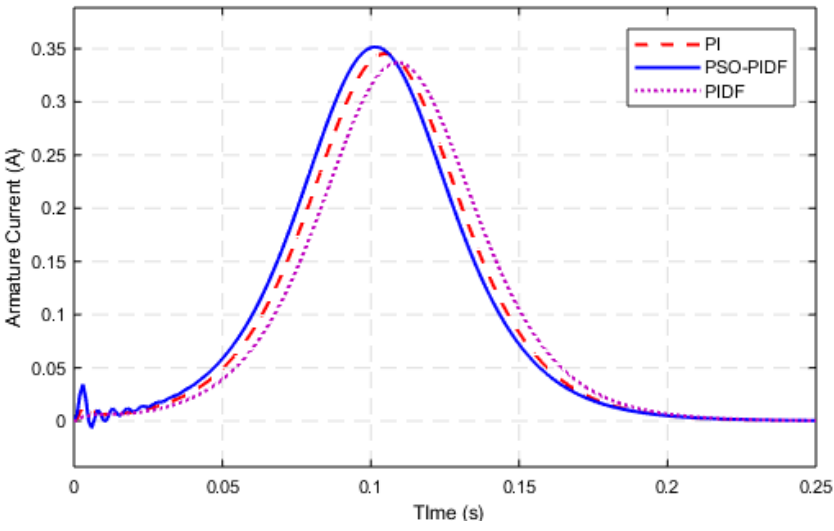

Fig. 5. Armature current response for PI and PIDF.

\section{CONCLUSION}

In this paper, the priority-based fitness approach is implemented on PSO algorithm to find the optimal gains of the PIDF controller for buck-converter driven DC motor. From the comparative assessment, the proposed tuning method has a significant improvement compared to PI controller and Simulink PID Tuner. Therefore, it is confirmed that the suggested tuning method can solve the control problem of buck-converter driven DC motor in aforesaid sectors. A future study investigating an experimental works on buck-converter driven DC motor system by implementing an online model-free controller would be very interesting.

\section{ACKNOWLEDGMENT}

This research was financed by Universiti Teknikal Malaysia Melaka under research grant PJP/2018/FTK(10B)/S01610.

\section{REFERENCES}

1. F. Antritter, P. Maurer, and J. Reger, "Flatness based control of a buck-converter driven DC motor," Proc. $4^{\text {th }}$ IFAC Symposium on Mechatronic Systems, vol. 4, Part 1, 2006.

2. I. Boldea and S.A. Nasar, Electric Drives. Boca Raton, FL: CRC Press LLC, 1999.

3. J. Linares-Flores and H. Sira-Ramirez, "A smooth starter for a DC machine: a flatness based approach," Proceedings of 1st International Conference on Electrical and Electronics Engineering and X Conference on Electrical Engineering, 2004, pp. 589-594. 
4. R. M. T. Raja Ismail, M. A. Ahmad, and M. S. Ramli, "Speed control of buck-converter driven DC motor using LQR and PI: A comparative assessment," Proc. of Int. Conference on $3^{\text {rd }}$ Asia Modelling and Simulation, 2009, pp. 97-101.

5. R. M. T. Raja Ismail, M. A. Ahmad, and M. S. Ramli, "Speed control of buck-converter driven DC motor based on smooth trajectory tracking," Proc. of Int. Conference on Information management and Engineering, 2009, pp. 651-655.

6. M. Z. M. Tumari, M. S. Saealal, M. R. Ghazali, and Y. A. Wahab, "Hinfinity with pole placement constraint in LMI region for a buck-converter driven DC motor," Proc. IEEE Int. Conf. Power Energy, Kota Kinabalu, Sabah, Malaysia, Dec. 2-5, 2012, pp. 530-535.M.

7. M. A. Ahmad and R. M. T. Raja Ismail, "A data-driven sigmoid-based PI controller for buck-converter powered DC motor", IEEE Symposium on Computer Applications \& Industrial Electronics, Langkawi, Malaysia, Apr. 24-25, 2017, pp. 81-86.

8. M. A. Ahmad, R. M. T. Raja Ismail, and M. S. Ramli, "Control strategy of buck converter driven DC motor: A comparative assessment," Australian Journal of Basic Applied Sciences, vol. 4(10), 2010, pp. 4893-4903.

9. T. K. Roy, L. C. Paul, M. I. Sarkar, M. F. Pervej, and F. K. Tumpa, "Adaptive Controller Design for Speed Control of DC Motors Driven by a DC-DC Buck Converter”, International Conference on Electrical, Computer and Communication Engineering (ECCE), Cox's Bazar, Bangladesh, February 16-18, 2017, pp. 100-105.

10. M. Z. Mohd Tumari, M. A. Ahmad, M. S. Saealal, M. A. Zawawi, Z. Mohamed and N. M. Yusop, "The direct strain feedback with PID control approach for a flexible manipulator: Experimental results,' 11th Int. Conf. on Control, Automation and Systems (ICCAS), 26-29 Oct 2011, South Korea, pp 7-12.

11. A. N. K. Nasir, M. Z. Mohd Tumari and M. R. Ghazali, "Performance comparison between Sliding Mode Controller SMC and Proportional-Integral-Derivative PID controller for a highly nonlinear two-wheeled balancing robot," 13th International Symposium on Advanced Intelligent Systems (ISIS), 20-24 Nov 2012, Kobe, Japan, pp. 1403-1408.

12. M. Z. Mohd Tumari, M. S. Saealal, W. N. Abd Rashid, S. Saat, M. A. Mohd Nasir," The Vehicle Steer by Wire Control System by Implementing PID Controller," Journal of Telecommunication, Electronic and Computer Engineering (JTEC), vol. 9 (3-2), 2017, pp. 43-47.

13. M. Z. Mohd Tumari, M. A. Mohd Nasir, M. S. Saealal, A. W. Ab Aziz, S. Saat, M. H. Suid, M. R. Ghazali, "The control scheme of vehicle steer by wire system by using PD-PID controller," Proceedings of Mechanical Engineering Research Day, 30 Mar 2017, UTeM, Melaka, pp. 13-14.

14. M. Z. Mohd Tumari, L. Shabudin, M. A. Zawawi, L. H. Ahmad Shah, "Active sway control of a gantry crane using hybrid input shaping and PID control schemes," IOP Conference Series: Materials Science and Engineering, vol. 50 (1), 2013, pp. 1-11.

15. A. Noordin, M. A. Mohd Basri, Z. Mohamed and A. F. Zainal Abidin, "Modelling and PSO Fine-tuned PID Control of Quadrotor UAV," International Journal on Advanced Science Engineering Information Technology, vol. 7 (4), 2017, pp. 1367-1373.

16. S. M. Girirajkumar, D. Jayaraj and A. R. Kishan, "PSO based Tuning of a PID controller for a High Performance Drilling Machine," International Journal of Computer Application, vol. 1 (19), 2010, pp. 12-18.

17. R. Ortega, A. Loria, P. J. Nicklasson, and H. Sira-Ramirez, Passivitybased Control of Euler-Lagrange Systems. London: Spinger, 1998.

18. H. I. Jaafar, Z. Mohamed, A. F. Zainal Abidin and Z. Ab Ghani, "PSO-Tuned PID controller for a Nonlinear Gantry Crane System," 2012 IEEE International Conference on Control System, Computing and Engineering, 23-25 Nov 2012, Penang, Malaysia, pp. 515-519.

19. A. Adam, A. F. Zainal Abidin, Z. Ibrahim, A. R. husain, Z. M. Yusof and I. Ibrahim, "A Particle Swarm Optimization Approach to Robotic Drill Route Optimization," Fourth Asia Int. Conf. Math. Model. Computer Simulation, 26-28 May 2010, pp. 60-64.

20. M. Abramowitz and I. A. Stegun, Handbook of Mathematical Functions with Formulas, Graphs, and Mathematical Tables, 9th printing. New York: Dover, 1972.

21. MathWorks

Homepage https://www.mathworks.com/help/slcontrol/gs/automated-tuning-of-si mulink-pid-controller-block.html, last accessed 2019/1/21.

\section{AUTHORS PROFILE}

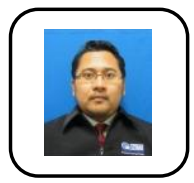

Mohd Zaidi Bin Mohd Tumari received B-Eng. in Electrical-Mechatronics August 2008 and M-Eng. In (Mechatronics \& Automatic Control) at UTM Malaysia, March 2010. Currently Lecturer at Universiti Teknikal Malaysia Melaka, Malaysia. His research interest in control of mechatronics systems, optimization and robotics (mohdzaidi.tumari@utem.edu.my).

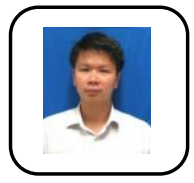

Amar Faiz Bin Zainal Abidin is a lecturer. He has a Master of Electrical (Mechatronics and Automatic Control) Engineering from UTM and Bachelor of Electrical \& Electronics Engineering from University of Nottingham. His research area includes swarm intelligence, computational intelligence and computer vision.

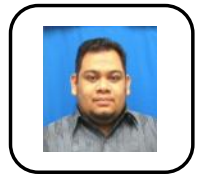

A Shamsul Rahimi Bin A Subki is a lecturer. He has a Master of Science (Microelectronics) from UKM and Bachelor of Engineering (Microelectronics Engineering) from UKM. His research area includes microelectronics, semiconductor and power electronics.

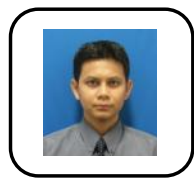

Ab Wafi Bin Ab Aziz is a lecturer. He has a Master of Engineering (Electrical-Mechatronic and Automatic Control) from UTM and Bachelor of Engineering (Electrical \& Electronics) from UTP. His research area includes control \& instrumentation.

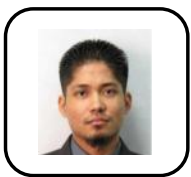

Mohd Ashraf Ahmad received B-Eng. in Electrical-Mechatronics June 2006, M-Eng. In (Mechatronics \& Automatic Control) at UTM Malaysia October 2007 and Doctor of Informatics (Systems Science), Kyoto University, Japan, March 2015. Currently Senior Lecturer at Universiti Malaysia Pahang, Malaysia. His research interest in model-free

control, vibration control, control of mechatronics systems and Identification of nonlinear systems (mashraf@ump.edu.my).

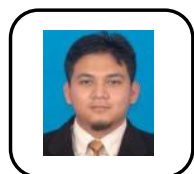

Mohd Riduwan Ghazali received B-Eng. in Electrical-Mechatronics August 2007 and MEng. in (Mechatronics \& Automatic Control) at UTM Malaysia Mei 2010. Currently Lecturer at Universiti Malaysia Pahang, Malaysia. His research interest in data-driven control, mechatronics system, robotics and control instrumentations (riduwan@ump.edu.my). 